\title{
Multiple Endocrine Neoplasia Type 1 Presenting with Hypoglycemia due to Insulinoma: A Case Report
}

Husain Taha Radhi", Riyadh Almerbati, Ebtihal Al yusuf, Rawdha Fardan, Hasan Farooq and Saeed Khalaf

Department of Endocrinology, Salmanyia Medical Complex, Ministry of Health, Bahrain

"Corresponding author: Husain Taha Radhi, Department of Endocrinology, Salmanyia Medical Complex, Ministry of Health, Bahrain, E-mail: husaintaha74@yahoo.com

Received date: December 11, 2018; Accepted date: December 24, 2018; Published date: January 03 , 2019

Copyright: (C) 2019 Radhi HT, et al. This is an open-access article distributed under the terms of the Creative Commons Attribution License, which permits unrestricted use, distribution, and reproduction in any medium, provided the original author and source are credited.

\begin{abstract}
Multiple Endocrine neoplasia type 1 is a rare, autosomal dominant disorder consisting of tumors of the parathyroid, pancreatic islets, and anterior pituitary. The incidence of insulinoma in multiple endocrine neoplasia is relatively uncommon. However, insulinoma is the most common cause of hyperinsulinemic hypoglycemia. We report a case of a 38-year-old female who presented to the emergency department because of frequent attacks of hypoglycemia in the form of diaphoresis, loss of consciousness, and tonic-clonic seizures. Parathyroidectomy was performed for her when she was 10 years old. After the biochemical and radiological investigation, she has been diagnosed with Multiple Endocrine neoplasia type 1 due to the presence of insulinoma, parathyroid adenoma, and a pituitary microdenoma. Insulinoma is a rare condition, however it should be encountered in the differential diagnosis of any young individual presenting with frequent hypoglycemic symptoms.
\end{abstract}

Keywords: Insulinoma; MEN1; Hypercalcemia; Hypoglycemia; Neuroendocrine tumor

\section{Introduction}

Multiple Endocrine neoplasia type 1 (MEN1) is a rare, autosomal dominant inherited endocrine disorder characterized by presentation of tumors of parathyroid glands, anterior pituitary, and pancreatic islet cells. MEN 1 is defined as the presence of two or more primary MEN tumor types, or occurrence of one of the MEN 1 associated tumor in family members of a patient with clinical diagnosis of MEN 1 [1].

Insulinoma is a functional neuroendocrine tumor that secretes insulin. It may be associated with other endocrine glands tumors in the multiple endocrine neoplasia type I (MEN I). It's the most common cause of hyperinsulinemic hypoglycemia and it's the second most common secreting pancreatic islets cell tumors associated with MEN1 after gastrinoma. Only 4-6\% of patients with insulinoma will develop MEN1 [1,2]. Sporadic insulinoma usually develops after the age of 40, but MEN associated insulinoma usually occurs before the age of 40 and even sometimes before 20 [3].

We report a lady who was diagnosed with MEN1 upon her presentation with hypoglycemia.

\section{Case Report}

A 38-year-old female presented to the emergency department with loss of consciousness. She has experienced recurrent attacks of palpitation, sweating, tremor, lightheadedness, seizure like movements and loss of consciousness for the past 6 months. She noticed that the symptoms disappeared after eating or ingestion of sugar. She denied taking any prescribed or over the counter medications. She didn't notice any change in her weight. She was referred previously to the psychiatrist, because of the unexplained loss of consciousness episodes and her treating physicians have cast doubt on the issue of intake of oral hypoglycemic agents by the patient. Parathyroidectomy was performed for her at the age of 10 years because of hypercalcemia, in which 3 parathyroid glands were removed and hyperplasia of the parathyroid glands were confirmed thereafter. However, her calcium level persisted to be at high levels. One of her sisters was operated for pancreatic tumor. She also had a significant family history of hypercalcemia in all her siblings and their children.

Physical examination revealed a well-nourished female. She weighed $63 \mathrm{~kg}$ with body mass index (BMI) of $24 \mathrm{~kg} / \mathrm{m}^{2}$. A horizontal old scar was found upon neck examination (Figure 1). Her abdomen was soft, and non-tender with no masses or organomegaly. Neurologic examination was normal.

Her blood glucose level was $35 \mathrm{mg} / \mathrm{dL}$ when she arrived at the emergency department. She was started on parenteral dextrose. Despite that she was receiving intravenous glucose, she continued to have hypoglycemia. Blood sample was drowned for insulin, C- peptide, cortisol, and glucose during the hypoglycemic attack. Results showed inappropriately normal insulin level and c-peptide in view of hypoglycemia (Table 1). Blood and urine screen for sulphonylurea were negative. Since the cortisol level was low during hypoglycemia, short Synacthen test has been performed which showed low basal cortisol level but normal adrenal response (Table 2). That was consistent with secondary adrenal insufficiency for which she was started on oral corticosteroid. Hypercalcemia work up was consistent with primary hyperparathyroidism (Table 3 ). Sestamibi parathyroid scintigraphy showed parathyroid adenoma on the left lower pole (Figure 2). Hypothalamic- pituitary hormonal assays were normal except for prolactin level (Thyroid Stimulating Hormone $1.83 \mathrm{mlU} / \mathrm{L}$, Thyroxin $13.0 \mathrm{pmol} / \mathrm{L}$, Follicular stimulating Hormone $4.8 \mathrm{IU} / \mathrm{L}$, Luteinizing Hormone $5.9 \mathrm{IU} / \mathrm{L}$, and Prolactin $38 \mathrm{ng} / \mathrm{mL}$ ). In the presence of primary hyperparathyroidism and hyperinsulinemic hypoglycemia, insulinoma and multiple endocrine neoplasia type 1 were suspected.

Image work up was conducted to rule out insulinoma as a cause of hyperinsulinemic hypoglycemia. Computed Tomography (CT) of the 
Citation: $\quad$ Radhi HT, Almerbati R, Yusuf EA, Fardan R, Farooq H et al. (2018) Multiple Endocrine Neoplasia Type 1 Presenting with Hypoglycemia due to Insulinoma: A Case Report . J Immuno Biol 3: 140. doi:10.4172/2476-1966.1000140

Page 2 of 5

abdomen revealed two well-defined, enhanced, lobulated pancreatic lesions, one was seen on the tail and measured $3.0 \times 2.1 \mathrm{~cm}$ and the other one was seen in the body and measured $1.4 \mathrm{~cm}$ (Figure 3 ).

\begin{tabular}{|c|c|c|c|}
\hline Test & Results & Reference Range & Unit \\
\hline Insulin & 15.5 & $2.6-37.6$ & $\mu \mathrm{IU} / \mathrm{ML}$ \\
\hline C-peptide & 1.05 & $0.25-1.28$ & $\mathrm{nmol} / \mathrm{L}$ \\
\hline Cortisol & 85 & $193-690$ & $\mathrm{nmol} / \mathrm{L}$ \\
\hline Glucose & 2.5 & $3.6-8.9$ & $\mathrm{nmol} / \mathrm{L}$ \\
\hline
\end{tabular}

Table 1: Laboratory tests during hypoglycemia.

\begin{tabular}{|c|c|c|c|}
\hline Test & Results & Reference Range & Unit \\
\hline ACTH & 2.1 & $<10.0$ & $\mathrm{pmol} / \mathrm{L}$ \\
\hline $\begin{array}{c}\text { Cortisol (zero } \\
\text { time) }\end{array}$ & 71 & $193-690$ & $\mathrm{nmol} / \mathrm{L}$ \\
\hline $\begin{array}{c}\text { Cortisol (30 } \\
\text { minutes) }\end{array}$ & 410 & $\mathrm{nmol} / \mathrm{L}$ \\
\hline $\begin{array}{c}\text { Cortisol (60 } \\
\text { minutes) }\end{array}$ & 597 & $\mathrm{nmol} / \mathrm{L}$ \\
\hline
\end{tabular}

Table 2: Synacthen test.

\begin{tabular}{|c|c|c|c|}
\hline Test & Results & Reference Range & Unit \\
\hline Calcium & 2.63 & $2.15-2.5$ & $\mathrm{mmol} / \mathrm{L}$ \\
\hline
\end{tabular}

\begin{tabular}{|c|c|c|c|}
\hline Magnesium & 0.60 & $0.74-1.0$ & $\mathrm{mmol} / \mathrm{L}$ \\
\hline Phosphorus & 1.0 & $0.81-1.45$ & $\mathrm{mmol} / \mathrm{L}$ \\
\hline Albumin & 39 & $35-52$ & $\mathrm{~g} / \mathrm{L}$ \\
\hline
\end{tabular}

Table 3: Laboratory tests for hypercalcemia work up.

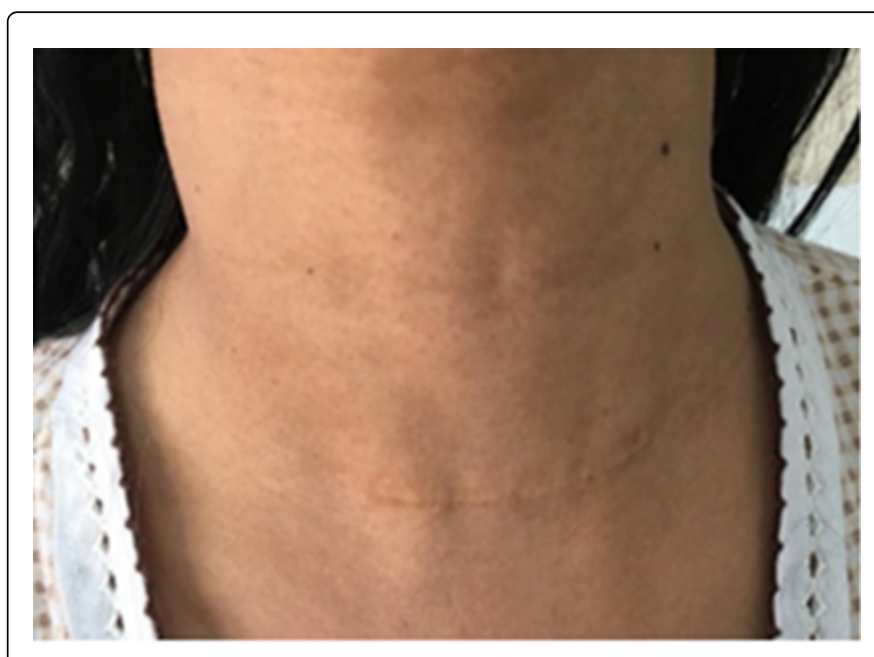

Figure 1: Neck of the patient is showing an old parathyroidectomy scar.

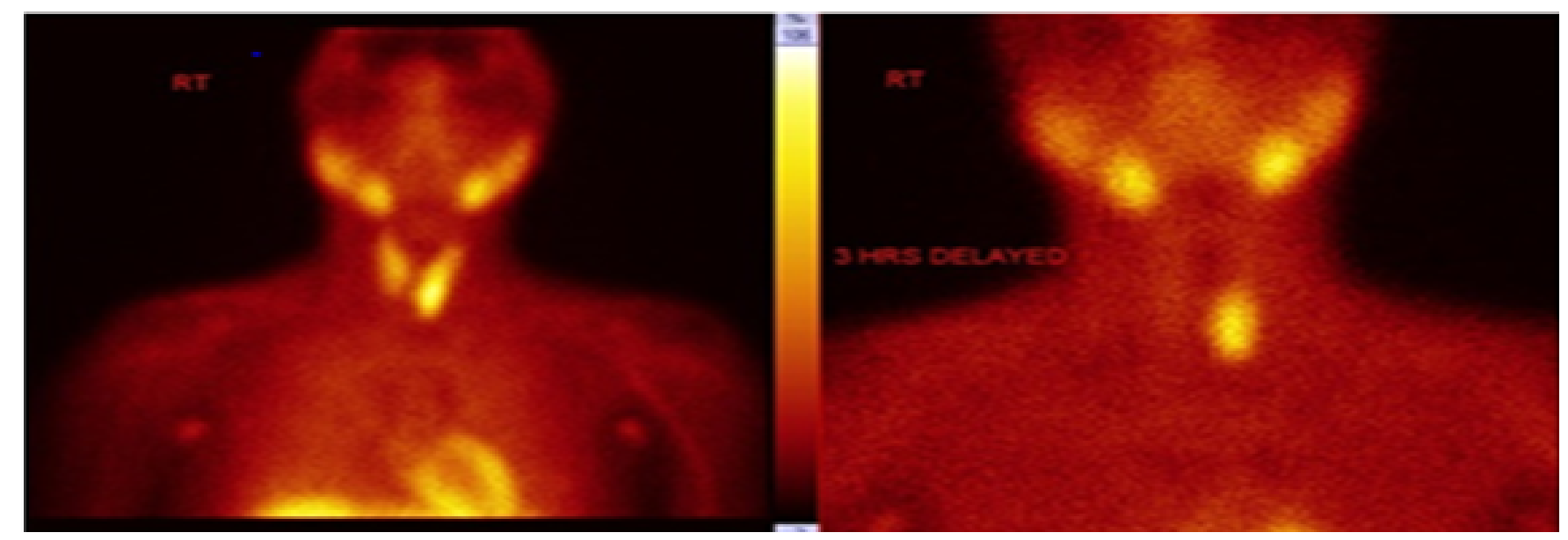

Figure 2: $99 \mathrm{~m}$ Tc-sesta MIBI Dual Phase Parathyroid Scintigraphy is showing retention of radiopharmaceutical left lower parathyroid gland in the delayed scan at $2 \mathrm{~h}$ P.I. The findings are consistent with left lower parathyroid adenoma.

The patient underwent laparoscopic distal pancreatectomy. Histopathological evaluation of the pancreatic mass was consistent with insulinoma which stained positive for chromogranin (Figures 5-7). Immediately after removal of the mass blood glucose level increased to $136 \mathrm{mg} / \mathrm{dL}$. She experienced no further hypoglycemic episodes postoperatively and the blood glucose levels were consistently in the normal range thereafter. She was discharged in a good health with proper glucose level. She was maintained on prednisolone $2.5 \mathrm{mg}$ once daily. Follow up appointment at endocrine clinic was given. 
Citation: $\quad$ Radhi HT, Almerbati R, Yusuf EA, Fardan R, Farooq H et al. (2018) Multiple Endocrine Neoplasia Type 1 Presenting with Hypoglycemia due to Insulinoma: A Case Report . J Immuno Biol 3: 140. doi:10.4172/2476-1966.1000140
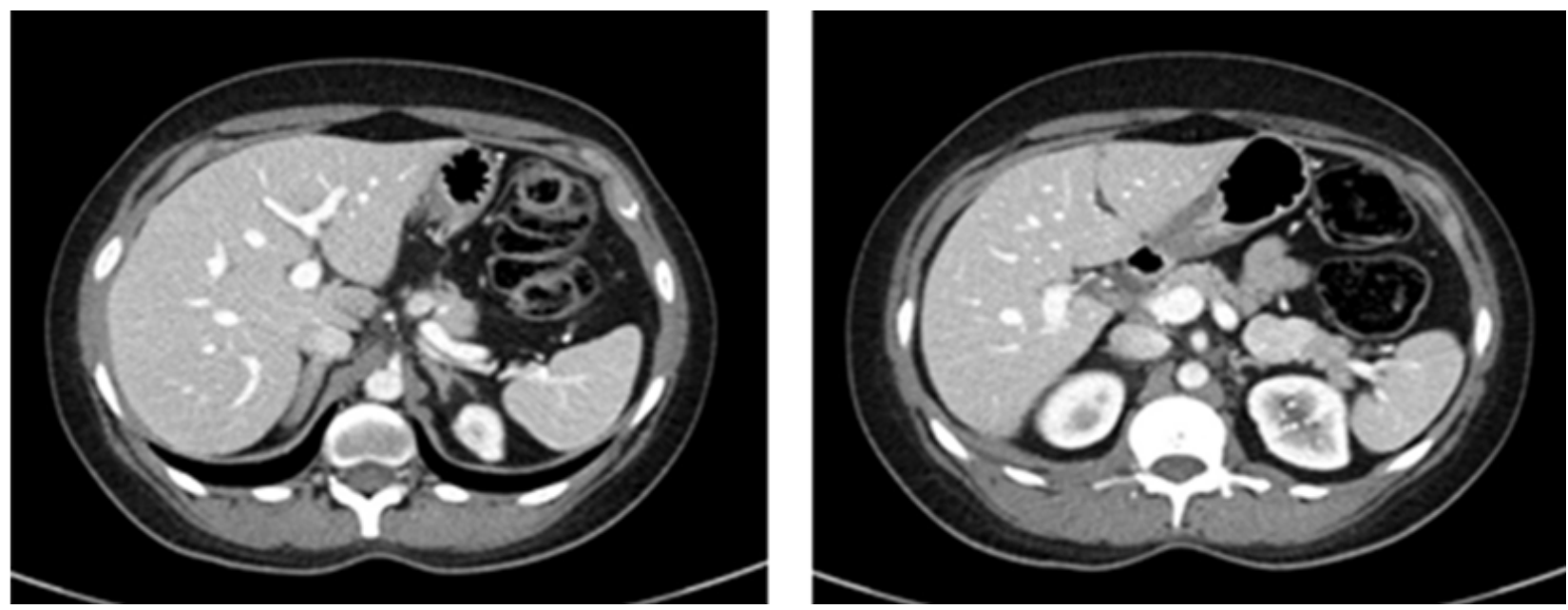

Figure 3: Contrast enhanced CT abdomen is showing two well-defined, enhanced, loculated pancreatic lesions, one was seen on the tail and measured $3.0 \times 2.1 \mathrm{~cm}$ and the other one was seen in the body and measured $1.4 \mathrm{~cm}$ which are highly suggestive of endocrine tumors.

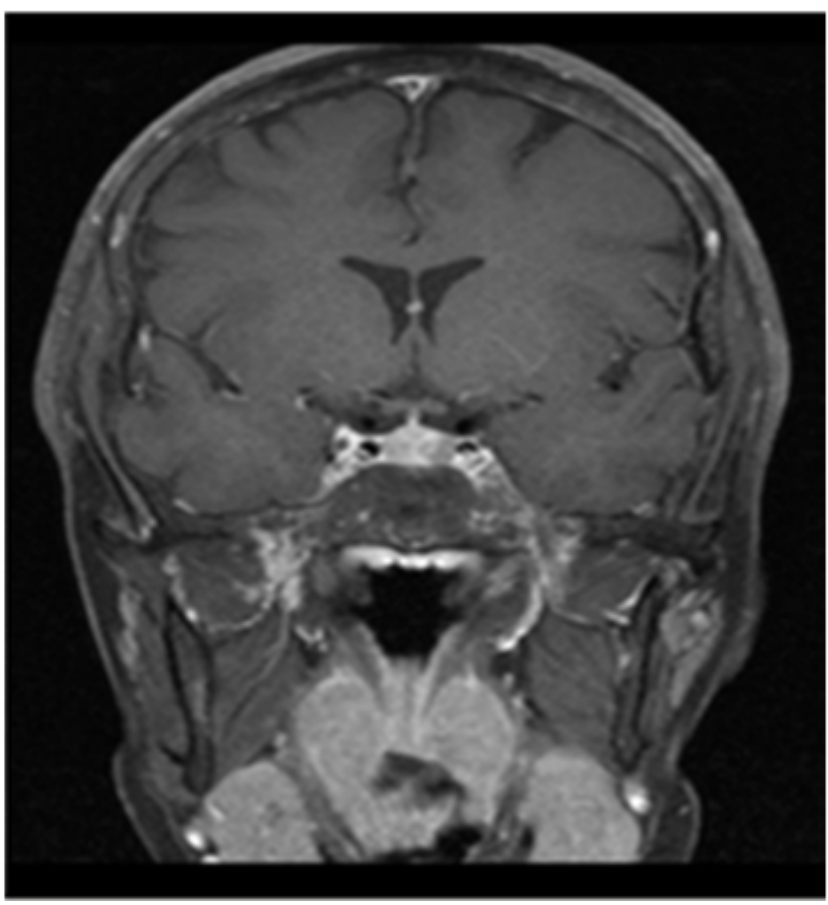

Figure 4: MRI of the pituitary gland is showing a $5.7 \mathrm{~mm}$ left sided pituitary microdenoma.

CT findings were highly suggestive of endocrine tumors in particular insulinoma. Magnetic Resonance Imaging (MRI) of the pituitary revealed a $5.7 \mathrm{~mm}$ left sided pituitary microdenoma with centrally located pituitary stalk (Figure 4 ).

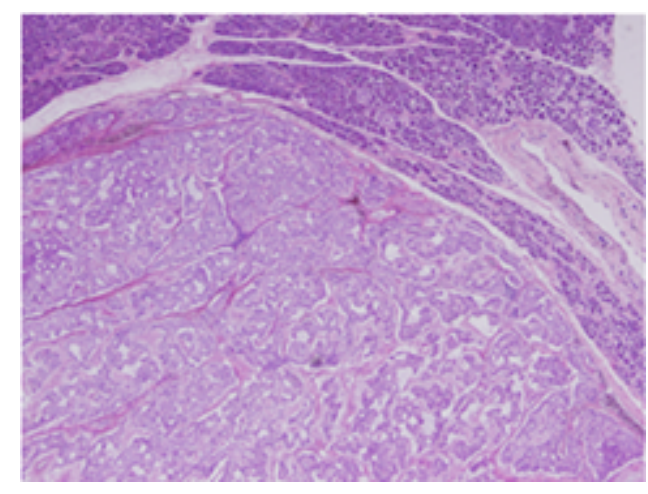

Figure 5: Low power magnification shows well circumscribed mass with gyriform pattern and patchy amyloid deposition (H\&E 40x).

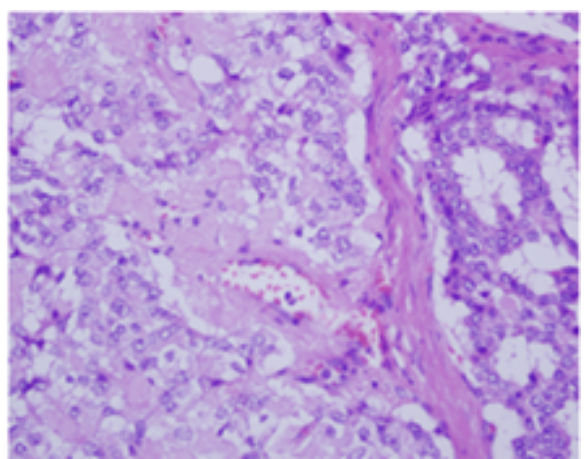

Figure 6: High power magnification shows neoplastic cells with saltand-paper chromatin and mild nuclear pleomorphism. Amyloid deposition is noted (H\&E 400x). 


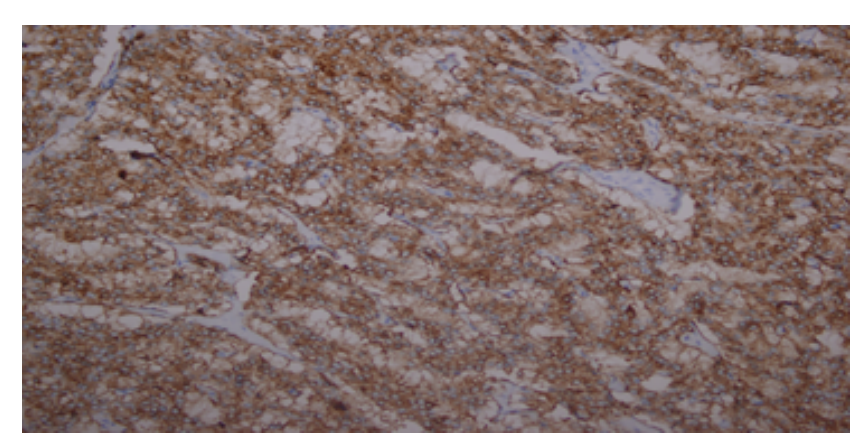

Figure 7: Tumor is positive for chromogranin immunostain (200x).

\section{Discussion}

MEN1 can be diagnosed clinically based on the presence of two or more MEN1- associated endocrine tumors [1]. A diagnosis of familial MEN1 is established in individuals with one of the MEN1 associated tumors who are first degree relatives of patients with a clinical diagnosis of MEN1. Genetic diagnosis of MEN1 is made in asymptomatic individuals and has not yet develops any of biochemical or radiological abnormalities indicative of tumor development but have germline MEN1 mutation [4]. Genetic study of MEN1 was not performed in our case because of the presence of insulinoma, parathyroid adenoma, and pituitary adenoma. Also, the family history of pancreatic tumor and hypercalcemia in her sister is highly suggestive of familial MEN1.

Parathyroid adenoma resulting in primary hyperparathyroidism is the most common feature of MEN1 and occurs in approximately $95 \%$ of MEN1 patients [5]. It is the earliest expression of MEN1. Primary hyperparathyroidism associated with MEN1 characterized by earlier age of onset compared with those without MEN1 (25-20 years vs. 55 years) [6]. That was consistent with our patient as her first presentation was at age of 10 years with hypercalcemia and parathyroid adenoma. We found many case reports which are in accordance with our case in showing that the earliest symptoms appeared between 5 and 11 years old $[7,8]$. In a large, multicenter MEN1study published by Goudet et al. showed that first symptoms were related to hyperparathyroidism in $75 \%$ and insulinoma in $12 \%$ of the patients. The first symptoms occurred before 10 years old in $14 \%$ and before 5 years old in 3\% [9].

$10-60 \%$ of patients with MEN1 have pituitary tumors being prolactinoma the commonest tumor and the majorities are microdenoma. The mean age of onset of pituitary tumors in patients with MEN1 has been reported to be $38.0 \pm 15.3$ years [10]. Insulinoma represent 10 to $30 \%$ of all pancreatic tumors in patients with MEN1 [5] and they occur in patients with MEN1 who are younger than 40 years and many occur in individuals at younger than 20 [6].

Whether parathyroidectomy for our patient was a right decision to take at age of 10 years old is questionable, because persistent or recurrence hypercalcemia is found in $40-60 \%$ of adult patients within 1 to 12 years. Therefore, the timing of surgery and the right operation during the first two decades need to be reviewed in young MEN1 patients.

Surgical treatment of insulinoma has been found to be curative in many patients. The 5- year and 10-year disease free survival rates are $100 \%$ and $96 \%$, respectively [11]. Insulinomas with MEN1 has been reported to have higher risk of malignancy than insulinomas without MEN1. However most of the patients with insulinoma with MEN1 have achieved hypoglycemia-free status after the surgery [12]. Our patient was advised to have a regular follow up since MEN1 patients are prone to have recurrent tumors. Medical management has been used in unresectable metastatic tumors, inoperable patients, persistent symptoms after unsuccessful operation, and patients refusing surgery. Recent reported techniques for the management of insulinoma are injection of octreotide; EUS guided alcohol ablation, embolization, and radiofrequency ablation [2].

Cases of insulinoma remains undiagnosed for months or even years. In our patient, the duration of symptoms of hypoglycemia prior to diagnosis was 4 months. Other case reports showed that the mean duration of symptoms prior to diagnosis ranges from several months to several decades [13]. The reason behind that is that the symptoms are not unique to insulinoma, so a high index of suspicion is mandatory.

In Conclusion, this case reports MEN1 in a 38-year-old lady who presented with severe hypoglycemia as a manifestation of underlying insulinoma. Insulinoma is a rare, mostly benign tumor, but can be lifethreatening by causing severe hypoglycemia. Insulinoma should always be considered in the differential diagnosis of all cases of non-diabetic hypoglycemia, since early detection and timely management could be lifesaving.

\section{References}

1. Thakker R, Newey P, Walls G, Bilezikian J, Dralle H, et al. (2012) Clinical Practice Guidelines for Multiple Endocrine Neoplasia Type 1 (MEN1). J Clin Endocrinol Metab, 97: 2990-3011.

2. Okabayashi T, Shima Y, Sumiyoshi T, Kozuki A, Ito S, et al. (2013) Diagnosis and management of insulinoma. World J Gastroenterol 19: 829-837.

3. Service F, Mcmahon M, O'Brien P, Ballard D (1991) Functioning Insulinoma-Incidence, Recurrence, and Long-Term Survival of Patients: A 60-Year Study. Mayo Clinic Proceedings 66: 711-719.

4. Turner J, Christie P, Pearce S, Turnpenny, P, Thakker R (2010) Diagnostic challenges due to phenocopies: lessons from Multiple Endocrine Neoplasia type1 (MEN1). Human Mutation 31: 1089-1101.

5. Brandi M, Gagel R, Angeli A, Bilezikian J, Beck-Peccoz P, et al. (2001) CONSENSUS: Guidelines for Diagnosis and Therapy of MEN Type 1 and Type 2. J Clin Endocrinol Metab 86: 5658-5671.

6. Eller-Vainicher C, Chiodini I, Battista C, Viti R, Mascia M, et al. (2009) Sporadic and MEN1 related primary hyperparathyroidism: Differences in clinical presentation and severity. J Bone Miner Res 24: 1404-1410.

7. Shepherd J (1991) The Natural History of Multiple Endocrine Neoplasia Type 1. Archiv Surg 126: 935-952.

8. Trump D, Farren B, Wooding C, Pang J, Besser G, et al. (1996) Clinical studies of multiple endocrine neoplasia type 1 (MEN1). QJM 89: 653-670.

9. Goudet P, Dalac A, Le Bras M, Cardot-Bauters C, Niccoli P, et al. (2015) MEN1 Disease Occurring Before 21 Years Old: A 160-Patient Cohort Study From the Groupe d'étude des Tumeurs Endocrines. J Clin Endocrinol Metab 100: 1568-1577.

10. Vergès B, Boureille F, Goudet P, Murat A, Beckers A, et al. (2002) Pituitary Disease in MEN Type 1 (MEN1): Data from the France-Belgium MEN1 Multicenter Study. J Clin Endocrinol Metab 87: 457-465.

11. Crippa S, Zerbi A, Boninsegna L, Capitanio V, Partelli S, et al. (2012) Surgical Management of Insulinomas. Arch Surg 147: 261-266.

12. Vezzosi D, Cardot-Bauters C, Bouscaren N, Lebras M, BertholonGrégoire M, et al. (2015) Long-term results of the surgical management of insulinoma patients with MEN1: a Groupe d'étude des Tumeurs Endocrines (GTE) retrospective study. Eur J Endocrinol 172: 309-319. 
Citation: $\quad$ Radhi HT, Almerbati R, Yusuf EA, Fardan R, Farooq H et al. (2018) Multiple Endocrine Neoplasia Type 1 Presenting with Hypoglycemia due to Insulinoma: A Case Report . J Immuno Biol 3: 140. doi:10.4172/2476-1966.1000140

Page 5 of 5

13. Brentjens R, Saltz L (2001) Islet cell tumors of the pancreas. Surg Clin North Am 81: 527-542. 